\title{
Endoscopic Fenestration of Multiloculated Post-Infectious Hydrocephalus
}

\author{
MOHAMMED H. EL-TANTAWY, M.D. \\ The Department of Neurosurgery, Faculty of Medicine, Benha University, Benha, Egypt
}

\begin{abstract}
Background: Loculated hydrocephalus is a condition of multiple cerebrospinal fluid filled loculi with or without communication with the ventricular system, and with tendency to enlarge and causing added problems to the patients. Endoscopic fenestration of the loculi should be considered the initial management for multiloculated hydrocephalus. It carries less morbidity and mortality compared to other methods of treatment with much better outcome. Multiloculated hydrocephalus caused by CNS infection is a special entity which is not well studied separately in the literature and it carries less favorable prognosis than other types caused by other etiologies.
\end{abstract}

Aim of Study: This study evaluated surgical results of post-infectious multiloculated hydrocephalus treated by endoscopic fenestration.

Patients and Methods: This is a retrospective study case series of 20 patients with multiloculated hydrocephalus due to previous attack of meningitis or shunt infection. All patients were treated surgically using endoscopic fenestration. Patients were followed after surgery for a period of time ranged from 6 to 30 months average 22 months during the period from June 2013 to December 2016.

Twenty patients with multiloculated hydrocephalus due to either known previous attack of meningitis in 13 patients $(65 \%)$ or as a sequele of repeated shunt infection in 7 patients (35\%) were included. All patients underwent endoscopic fenestration of the loculi with either shunt revision or placement of new shunt. All patients had recent brain CT scan and MRI scans preoperatively. Follow-up scans were evaluated regarding change in cysts size, disappearance of mass effect and restoration of the architecture of the brain sulci denoting improvement of hydrocephalus.

Results: Post-operative improvement in hydrocephalus occurred in 14 patients $(70 \%)$, while 3 patients $(15 \%)$ showed no improvement. Surgery has been terminated in 3 patients (15\%) overall patients needed shunt revisions were 14 (70\%). At the end of our follow-up period 9 patients $(45 \%)$ needed endoscopic fenestration one time again, 6 patients $(30 \%)$ needed 2 surgeries for endoscopic fenestration after the initial one with insertion of another shunt. 3 patients $(15 \%)$ repeated endoscopic fenestration for 3 times after the initial one with

Correspondence to: Dr. Mohammed H. El-Tantawy, E-Mail: hammad neurosurg@yahoo.com. placement of another shunt. Only 2 patients (10\%) continue without the need for any further surgeries.

Conclusion: Multiloculated hydrocephalus is a serious problem caused by different etiologies. Endoscopic fenestration considered the 1 st choice for solving this problem because of sound efficacy and less morbidity related to the procedure. Multiloculation caused by CNS infection has less favorable outcome than that caused by other etiologies.

Key Words: Endoscopic - Fenestration - Multiloculated Hydrocephalus.

\section{Introduction}

LOCULATED hydrocephalus, a condition of multiple cerebrospinal fluid filled loculi with or without communication with the ventricular system, and with tendency to enlarge and causing added problems to the patients. This condition has variable causes, but is commonly described as a sequlae of intraventicular hemorrhage, birth trauma, central nervous system infection, and even tumours [1-5]

Still real incidence of multiloculated hydrocephalus is not known, but given to the increasing survival of children from neonatal meningitis and intraventricular hemorrhage (the most common causes), it is not to be neglected [6].

Through literature, treatment of this condition is definitely surgical, described as challenging with poor outcome. Surgical options included; placement of multiple shunts [7], craniotomy and fenestration of septations [5,8], endoscopic fenestration of septations [9-13], or a combinations of these methods. Patients usually require repeated surgeries.

All these options used alone or in combination aimed to re communication of the loculi to the

\footnotetext{
Abbreviation:

MRI : Magneting Resonance Imaging.

VP shunt : Venticulo Peritoneal shunt.

EF : Endoscopic Fenestration.
} 
ventricular system towards an efficient CSF drainage in order to normalize intracranial pressure, avoid using multiple shunts, and this all together to treat patient's symptoms.

Endoscopic fenestration of the loculi has been used widely since the initial reports by Powers in 1990s [14]. It should be considered the initial management for multiloculated hydrocephalus [15] It carries less morbidity and mortality compared to other methods of treatment with much better outcome [16]

Multiloculated hydrocephalus caused by CNS infection is a special entity which is not well studied separately in the literature and it carries less favorable prognosis than other types caused by other etiologies.

\section{Patients and Methods}

This retrospective study was carried on 20 patients with multiloculated hydrocephalus due to either known previous attack of meningitis in 13 patients $(65 \%)$ or as a sequele of repeated shunt infection in 7 patients (35\%) without clear evidence of previous attack of meningitis.

All patients underwent endoscopic fenestration of the loculi with either shunt revision or placement of new shunt when needed aiming at converting the loculi into one cavity drained by minimum number of working shunts to control hydrocephalus and decrease number of needed shunts as much as possible.

Surgeries were done in the Department of Neurosurgery at Banha University Hospital and Banha Children Hospital between June 2013 and December 2016.

Detailed history taking from the family was obtained with special consideration to previous attacks of CNS infection, previous V-P shunt surgery and if any shunt revision was done before. General and neurological examination were carried out with recording of the head circumference and comparing it to head circumference follow-up charts and to the average normal measurements for age.

All patients had recent brain CT scan and MRI scans pre-operatively. Scans were repeated at 2 weeks after surgery and on regular intervals of 3 , 6 , and 12 months. In some cases we did not follow this order due to the development of new symptoms or malfunction of the present shunt. CT brain with intraventricular injection of contrast material was needed in 4 patients due to persistence of symptoms despite of normal looking MRI scans to ensure free communication between all the cysts and the ventricular system.

Follow-up scans were compared to the preoperative ones regarding change in cysts size, disappearance of mass effect and restoration of the architecture of the brain sulci denoting improvement of hydrocephalus.

Patients were also followed clinically for appearance of new symptoms as progressive increase in head circumference, delayed filling reservoir, convulsions, regression in milestones and any other symptoms or signs that may indicate increase intracranial pressure. Development of any of the previous symptoms and/or increase in the previously improved hydrocephalus was an indication for repeating the scans and considering repeating endoscopic fenestration and/or shunt revision.

Number of shunt revisions needed and necessity to do another surgery were recorded during the follow-up period.

Surgery was done under general anesthesia after good preoperative planning to the entry points and the trajectories after good analysis of the preoperative MRI scans. Entry points were determined so that we could fenestrate maximum number of cysts with least number of burr holes. Head position is adjusted so that the entry point is at the highest point of the head as much as possible. Burr holes with undermining the edges to facilitate rotating the scope during navigation. Dura is usually opened by straight incision to act like valve around the scope shaft. We used rigid cranial endoscope $2.8 \mathrm{~mm}$ diameter with one main working channel and 2 side channels for irrigation. At the beginning we navigate with the endoscope to identify the surrounding anatomy, then cyst fenestration is made using bipolar electrocautary. Widening of the fenestration is made by fogarty balloon dilatation or connecting multiple small fenestration together.

The final window should be at least $1 \mathrm{CM}$ in diameter to prevent early closure. The cyst wall was usually devascularized aiming to prevent the recurrence. Hemostasis was usually achieved by using warm lactated ringer irrigation or sometimes bipolar coagulation.

Patients with shunt malfunction were treated at the same session by endoscopic dissection of the adhesions around the ventricular catheter then redirect the catheter in different direction under endoscopic vision, or sometimes we replaced it if there is any doubt of shunt infection. 
Post-operatively patients were sent to the pediatric Intensive Care Unit for one night, then transferred to the ward until discharge.

\section{Results}

All the twenty patients included in this study had multiloculated hydrocephalus due to sequele of CNS infection. 13 patients $(65 \%)$ presented as sequele of previous attack of meningitis, $10(50 \%)$ of them had V-P shunt as a treatment, while 3 patients $(15 \%)$ presented for the 1 st time after meningitis without having V-P shunt. 7 patients (35\%) presented with multiloculated hydrocephalus as a sequele of repeated shunt infection without evidence of previous attack of meningitis.

Patients included were 11 boys and 9 girls. Age ranged from (5-36 months) mean 14 months, and have been followed for (6-30 months) average 22 months.

The main presenting symptoms were shunt malfunction with progressive increase in head circumference in 11 patients (55\%), progressive increase in head circumference with normal working shunt in 6 patients $(30 \%)$ and progressive increase in head circumference without previous shunt in 3 patients (15\%). In these 3 patients new shunts has been placed.

Other associated symptoms include regression in milestones and newly developed epilepsy and other symptoms of increased intracranial pressure. Patient demographics is shown in (Table 1).

Post-operative improvement in hydrocephalus occurred in 14 patients $(70 \%)$ as evidenced by early follow-up images, while 3 patients (15\%) showed no improvement due to large number of cysts that could not be fenestrated all at the same session. Another surgery was planned for those 3 patients with different entry points and different trajectories. Surgery has been terminated in 3 patients (15\%); 2 of them due to bleeding and 1 due to improper visualization due to high protein content of the CSF. In those 3 patients EVD (external ventricular drainage) was done until CSF became clear and then endoscopic fenestration was repeated. Table (2) shows early surgical outcome.

All the 11 patients with pre-existing malfunctioned shunt had shunt revision initially and again one more time during the follow-up period, while 3 out of the 6 patients with working shunt initially, needed shunt revision once till the end of the follow-up period. The last 3 patients with newly inserted shunts at time of surgery continued all without the need for shunt revision till the end of the follow up period. Overall patients with shunt revisions were 14 (70\%). Table (3) shows shunt revision rates among patients in this study.

At the end of our follow-up period, 9 patients (45\%) needed endoscopic fenestration one time again [6 with pre existing working shunt, 2 with pre existing malfunctioned shunt and 1 without pre existing shunt].

6 patients (30\%) needed 2 surgeries for endoscopic fenestration after the initial one with insertion of another shunt. All these 6 patients had malfunctioned shunts at initial presentation.

3 patients (15\%) had repeated endoscopic fenestration for 3 times after the initial one with placement of another shunt, all of them had preexisting nonfunctioning shunts (Table 4).

The total number of patients needed another V-P shunt in this study was 9 patients (45\%).

Only 2 patients $(10 \%)$ continue without the need for any further surgeries till the end of the follow-up period. These 2 patients had endoscopic fenestration prior to the initial shunt placement.

Table (5) shows initial presentation of VP shunt in relation to number of endoscopic fenestrstion needed.

Peri operative complications encountered in this study are shown in (Table 6).

Table (1): Patient demographics.

\begin{tabular}{|c|c|}
\hline Item & Description \\
\hline - Total No. of patients & 20 \\
\hline - Male: Female & $11: 9$ \\
\hline - Age (months) & Range (5-36)-mean 14 \\
\hline - Cause of multiloculation & $\begin{array}{l}\text { - } 13(65 \% \text { patients: } \\
\text { - Sequele of previous attack of } \\
\text { meningitis } \\
\text { - } 10(50 \%) \text { patients with old V-P shunt } \\
\text { - } 3(15 \%) \text { patients presented without } \\
\text { V-P shunt. } \\
\text { - } 7(35 \%) \text { patients: } \\
\text { - Sequele of repeated shunt infection }\end{array}$ \\
\hline - Main presenting symptom & $\begin{array}{l}\text { - } 11(55 \%) \text { patients: } \\
\text { - Increased head circumference with } \\
\text { malfunctioned shunt } \\
\text { - } 6(30 \%) \text { patients: } \\
\text { - Increased head circumference with } \\
\text { normal working shunt } \\
\text { - } 3(15 \%) \text { patients: } \\
\text { - Increased head circumference } \\
\text { without previous shunt }\end{array}$ \\
\hline - Follow-up period (months) & Range (6-30)-mean 22 \\
\hline
\end{tabular}


Table (2): Early surgical outcome.

\begin{tabular}{ll}
$\begin{array}{l}\text { No. of } \\
\text { patients }\end{array}$ & Early surgical outcome \\
\hline $14(70 \%)$ & Improved hydrocephalus \\
$3(15 \%)$ & No improvement \\
$2(10 \%)$ & Termination of surgery due to bleeding \\
$1(5 \%)$ & Termination of surgery due to improper visualization \\
\hline
\end{tabular}

Table (3): Shunt revision rates.

\begin{tabular}{ll}
\hline No. of patients & Shunt revision rate \\
\hline - 11 patients with pre existing & $\bullet 11 / 11$ of them $(100 \%)$ needed \\
malfunctioned shunts. & revision. \\
- 6 patients with pre existing & $-3 / 6$ of them $(50 \%)$ needed \\
working shunts. & revision. \\
- 3 patients with newly inserted & $\begin{array}{l}0 / 3 \text { none of them }(0 \%) \text { needed } \\
\text { shunts. }\end{array}$ \\
\hline Total No. patients needed revision. & $-14 / 20$ patients $(70 \%)$ \\
\hline
\end{tabular}

Table (4): No. of endoscopic fenestration needed during the follow-up period.

\begin{tabular}{lll}
$\begin{array}{l}\text { No. of additional } \\
\text { Endoscopic } \\
\begin{array}{l}\text { Fenestration (EF) } \\
\text { needed during } \\
\text { follow-up period }\end{array}\end{array}$ & $\begin{array}{c}\text { No. of } \\
\text { patients }\end{array}$ & $\begin{array}{c}\text { Condition of the shunt } \\
\text { at initial presentation }\end{array}$ \\
\hline No additional EF & $2(10 \%)$ & No previous shunt. \\
1 additional EF & 6 & $\begin{array}{l}\text { Previous functioning shunt. } \\
\text { Previous non functioning shunt. } \\
\text { No previous shunt. }\end{array}$ \\
2 additional EF & $6(30 \%)$ & Previous non functioning shunt. \\
3 additional EF & $3(15 \%)$ & Previous non functioning shunt. \\
\hline
\end{tabular}

Table (5): Initial presentation of VP shunt in relation to number of endoscopic fenestrstion needed.

\begin{tabular}{lcc}
$\begin{array}{l}\text { Initial presentation } \\
\text { of the V-P shunt }\end{array}$ & No. of patients & $\begin{array}{c}\text { No. of additional } \\
\text { EF needed }\end{array}$ \\
\hline Non functioning & $11 \quad \begin{array}{l}2 / 11(18.2 \%) \\
6 / 11(54.5 \%)\end{array}$ & $\begin{array}{l}1 \mathrm{EF} \\
2 \mathrm{EF} \\
3 / 11(27.3 \%)\end{array}$ \\
$\begin{array}{llll}3 \mathrm{EF} \\
\text { Functioning }\end{array}$ & $6 \quad 6 / 6(100 \%)$ & $1 \mathrm{EF}$ \\
No previous shunt & $3\} \begin{array}{l}2 / 3(66.7 \%) \\
1 / 3(33.3 \%)\end{array}$ & $\begin{array}{l}\text { No EF } \\
1 \mathrm{EF}\end{array}$ \\
\hline
\end{tabular}

Table (6): Complications.

\begin{tabular}{ll}
\hline Complications & No. of patients \\
\hline Intra operative bleeding & $2(10 \%)$ \\
Circulatory over load & $1(5 \%)$ \\
Seizure & $1(5 \%)$ \\
Neurological insult & 0 \\
Death & 0 \\
\hline
\end{tabular}
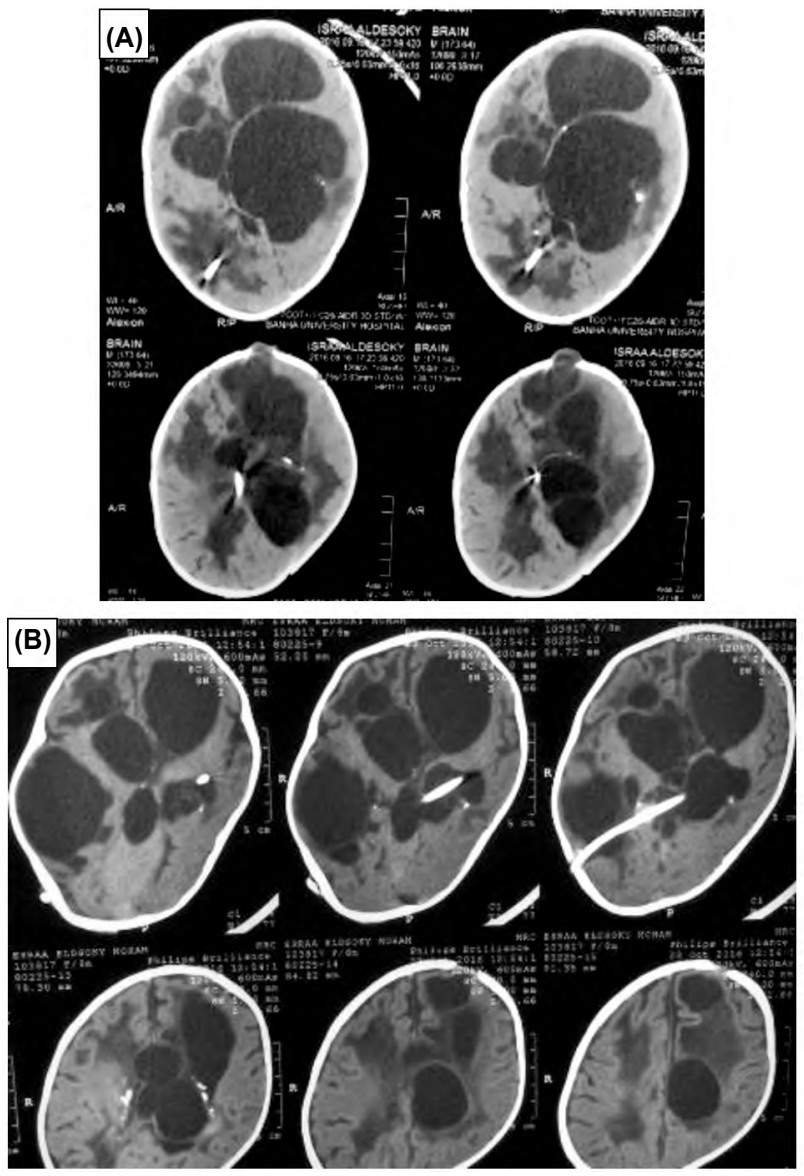

Fig. (1): (A) Pre-operative CT scan for a patient with multiloculated hydrocephalus with previous endoscopic fenestration and previous VP shunt showing obtruction of the shunt and recurrence of loculation. (B) Post-operative $\mathrm{CT}$ of the same patient after redoing the endoscopic fenestration and revision and redirection of the shunt.

\section{Discussion}

Multiloculated hydrocephalus is a condition in which there is isolated CSF compartments within the ventricular system that tend to enlarge even if the patient has a functioning V-P shunt. These compartments are separated by septa that prevent accumulated CSF from being absorbed by either the ventricular catheter or normal sites of CSF absorbtion [6].

Multiloculation is a serious problem that usually develop as a complication of meningitis, intraventricular hemorrhage, post shunt infection, head injury, ependymal trauma during shunt insertion and other inflammatory processes [17].

More than $30 \%$ of infants who survive after an attack of neonatal meningitis will develop hydrocephalus, most of these neonates have a risk of having multiloculated hydrocephalus [18] 
It is estimated that multiloculation occur in a percentage reaching $20 \%$ of all hydrocephalic neonates in many studies $[\mathbf{5 , 1 5 , 1 9 ]}$.

Most studies for multiloculated hydrocephalus and its therapeutic options, described the condition without focusing on one main etiology behind this pathology. In this study we described only cases of multiloculated hydrocephalus that complicate CNS infection as the main cause of compartmentalization, thus we included only post meningetic and post shunt infection cases, because this group represent the most challenging part in management, also their incidence and prognosis is not clear as a separate entity in the literature.

Neonatal meningitis as an etiological factor for multiloculation was associated with ventriculitis in $75-92 \%$ of cases $[\mathbf{6 , 2 0}$. Inflammatory process of the ependymal wall of the ventricle lead to proliferation of sub ependymal glia. Exudates from inflammatory process then organize and fibroglial webs appear and project into the lumen and the process of intraventricular septations starts [3,21,22]

Although shunt infection is also associated with formation of septa, Jamjoom et al., found that a predisposing factor like intraventricular hemorrhage or neonatal meningitis, as initial cause of hydrocephalus, is usually present when loculation follows shunt infection [3].

Different methods of treatment has been described in the literature. Insertion of multiple shunts has been associated with high risk of shunt infection and high morbidity rates [23]. Some authors reported good results with microsurgical fenestration of the intraventricular septa, however craniotomy with trans cortical or trans callosal approaches have their own surgical risks $[\mathbf{5 , 8 , 2 4}]$. Stereotactic aspiration of the cysts is associated with high incidence of recurrence thus it is not good option for multiloculation [25].

There is general agreement that endoscopic fenestration should be the 1st option for patients with multiloculation $[15,16,26-28]$. In most of these endoscopic studies, shunts were placed for patients before endoscopic fenestration and they concluded that endoscopic fenestrationhas reduced significantly the need for shunt revision/year following the fenestration.

Akabri etal in their study, compared the outcome of open surgery versus endoscopic fenestration in management of multiloculated hydrocephalus. Although they included different forms of complex multiloculation of different etiologies, they found that subsequent shunt revision rate was 0.74 intervention per year in the craniotomy group compared to 0.5 in the endoscopy group, and that $50 \%$ of patients in craniotomy group needed additional fenestration compared to $38.9 \%$ in the endoscopy group [26]

El-Ghandour reported that shunt revision rates were reduced from 2.9 per year before endoscopic fenestration to 0.2 per year after endoscopic fenestration [23]. Again this study included patients with multiloculation due to many etiological factors not only infection. This study included only patients with post infection etiology, so poorer prognosis was foundcompared to El-Ghandour study.

14 patients (70\%) in our study needed shunt revision or replacement somehow during the follow-up period. $100 \%$ of the patients who had malfunctioned shunt before endoscopic fenestration needed another revision compared to only $50 \%$ of patients who had pre existing working shunt. This might be related to complexity of loculations in the ${ }^{\text {st }}$ group and the higher probability of shunt infection in them.

El-Ghandour also found that none of the patients in whom endoscopic fenestration preceded shunt placement required shunt revision during the mean follow-up period. Results in this study support this finding in which all patients who had no pre existing shunts before endoscopic fenestration, did not need any shunt revisions during the follow-up period. This may be due to early diagnosis and management of these patients [23].

In this study, 14 patients (70\%) with pre existing shunts prior to endoscopic fenestration, required shunt revisions. This supports that pre existing shunts in multiloculated post infectious hydrocephalus may increase the failure rate of endoscopic fenestration.

Spennato et al., explained high incidence of shunt obstruction in multiloculation by the chronic inflammation of the ependyma and appearance of new septa. They considered multiloculated hydrocephalus as progressive disease [29].

Akbari et al., found that $38.5 \%$ of patients with multiloculated hydrocephalus required additional endoscopic fenestrations after the initial surgery, while El-Ghandour found that in 33\% of patients endoscopic fenestration was repeated during the follow-up period $[23,26]$.

In this study $90 \%$ of patients needed endoscopic fenestration to be repeated. This big difference in 
results may be related to the high incidence of reclosure and formation of new cysts in post infectious cases.

El-Ghandour found that $50 \%$ of patients with pre existing complex shunts, simplification were performed in which multiple pre existing shunts were replaced by only one [23]. In this study none of the patients started with multiple shunts but at the end of the follow-up 9 patients $(45 \%)$ ended up having 2 shunts.

Improvement of hydrocephalus was found in $75 \%$ of patients after initial endoscopic fenestration in El-Ghandour study compared to $70 \%$ in this study.

Avoiding shunts was impossible in this study due to the nature of the etiology that initiated multiloculation which is responsible for defective absorption of the CSF by arachnoid granulations. Eliminating the need for shunt after endoscopic fenestration was reported to be $12.5 \%$ in one study [23].

Although endoscopic fenestration is associated with less perioperative morbidity in most studies compared to other surgical methods, it may carry the risk of uncontrollable bleeding with sub optimal control, that may ended up in catastrophic events $[15,17,23,26,29]$. In this study complications were limited to minor intra operative bleeding in 2 patients $(10 \%)$, in which surgery was terminated due to improper visualization. External ventricular drain was placed until CSF cleared then endoscopic fenestration repeated again. 1 patient $(5 \%)$ showed postoperative tachycardia with chest crepitations due to circulatory overload. This patient improved by conservative treatment. Seizure occur in 1 patient $(5 \%)$ no reported deaths post-operative neurological insults.

For better localization of the cysts some authors advocate the use of intra operative navigation as localizing tool in complex multiloculated cases [30] Navigated neuroendoscopy is still of doubtful value due to early brain shift after opening the cyst. Intra operative ultrasonography has been used by others [23]. Pre-operative planning in this study depended mainly on proper reading of the coronal, sagittal, axial MRI scans to have 3 dimensional orientation. Sometimes we used more than one burr hole to fenestrate multiple cysts without damaging important vascular and neural structures.

\section{Conclusion:}

Multiloculated hydrocephalus is a serious problem caused by different etiologies. Endoscopic fenestration considered the 1 st choice for solving this problem because of sound efficacy and less morbidity related to the procedure. Multiloculations caused by CNS infection has less favorable outcome than that caused by other etiologies. Early diagnosis and management is associated with better outcome and may decrease the number of shunts needed.

Further larger studies is needed to evaluate the outcome of endoscopic fenestration in post infectious multiloculated hydrocephalus compared to other modalities of treatment and to other etiologies.

\section{Declarations:}

\section{Acknowledgment:}

The authors thank all parents of included patients.

Funding:

This study had no funding from any resource.

\section{Competing interests:}

The authors declare that they have no conflict of interest.

\section{Ethical approval:}

This research accepted by Research Ethics Committee (REC) of Faculty of Medicine, Benha University (Chairman: Prof./Ibrahim El-Gendy).

All procedures performed in studies involving human participants were in accordance with the ethical standards of the institutional and/or national research committee and with the 1964 Helsinki declaration and its later amendments or comparable ethical standards. A written informed consent was obtained from parents of patients after explaining all steps of this study.

\section{Authors' contributions:}

Mohammed H. El-Tantawy performed the operative and clinical parts of the study, and analyzed the data and wrote the paper with careful revision of the final version of the manuscript.

\section{References}

1- ELLER T.W. and PASTERNAK J.F.: Isolated ventricles following intraventricular hemorrhage. J. Neurosurg., 62: 357-62, 1985.

2- HANDLER L.C. and WRIGHT M.G.: Postmeningitic hydrocephalus in infancy. Ventriculography with special reference to ventricular septa. Neuroradiology, 16: 31-5, 1978.

3- JAMJOOM A.B., MOHAMMED A.A., AL-BOUKAI A., JAMJOOM Z.A., RAHMAN N. and JAMJOOM H.T. Multiloculated hydrocephalus related to cerebrospinal fluid shunt infection. Acta. Neurochir. (Wien), 138 (6): 714-9, 1996. 
4- KALSBECK J.E., DeSOUSA A.L., KLEIMAN M.B. GOODMAN J.M. and FRANKEN E.A.: Compartmentalization of the cerebral ventricles as a sequela of neonatal meningitis. J. Neurosurg., 52: 547-52, 1980.

5- NIDA T.Y. and HAINES S.J.: Multiloculated hydrocephalus: Craniotomy and fenestration of intraventricular septations. J. Neurosurg., 78: 70-6, 1993.

6- SPENNATO P., CINALLI G., CARANNANTE G., RUGGIERO C. and DEL M.L.: Multiloculated hydrocephalus. In: Cinalli G., Maixner W.J., Sainte-Rose C., editors. Pediatric Hydrocephalus. Milan: Springer, p. 219-44, 2004.

7- KAISER G.: The value of multiple shunt systems in the treatment of nontumoral infantile hydrocephalus. Child's Nerv. Syst., 2: 200, 1986.

8- SANDBERG D.I., McCOMB G. and KREIGER M.D.: Craniotomy for fenestration of multiloculated hydrocephalus in pediatric patients. Neurosurgery, 57 (1 Suppl): 100-6, 2005.

9- FRITSCH M.J. and MEHDORN M.: Endoscopic intraventricular surgery for treatment of hydrocephalus and loculated CSF space in children less than one year of age. Pediatr. Neurosurg., 36: 183-8, 2002.

10- NOWOSLAWSKA E., POLIS L., KANIEWSKA D., MIKOAJCZYK W., KRAWCZYK J., SZYMASKI W., et al.: Effectiveness of neuroendoscopic procedures in the treatment of complex compartmentalized hydrocephalus in children. Childs. Nerv. Syst., 19: 659-65, 2003.

11- EL-GHANDOUR N.M.: Endoscopic cyst fenestration in the treatment of uniloculated hydrocephalus in children. J. Neurosurg. Pediatr., Apr., 11 (4): 402-9, 2013.

12- SCHULZ M., BOHNER G., KNAUS H., HABERL H and THOMALE U.W.: Navigated endoscopic surgery for multiloculated hydrocephalus in children. J. Neurosurg. Pediatr., 5: 434-42, 2010.

13- TEO C., KADRIAN D. and HAYHURST C.: Endoscopic management of complex hydrocephalus. World Neurosurg., 79: S21.e1-7, 2013.

14- POWERS S.K.: Fenestration of intraventricular cysts using a flexible, steerable endoscope. Acta. Neurochir. Suppl., 54: 42-6, 1992.

15-LEWIS A.I., KEIPER G.L. and CRONE K.R.: Endoscopic treatment of multiloculated hydrocephalus. J. Neurosurg., 82: 780-5, 1995.

16- ZUCCARO G. and RAMOS J.G.: Multiloculated hydrocephalus. Childs. Nerv. Syst., Oct., 27 (10): 1609-19, 2011.

17- ANDRESEN M. and JUHLER M.: Multiloculated hydrocephalus: A review of current problems in classification and treatment. Childs. Nerv. Syst., Mar., 28 (3): 357-62, 2012
18- REINPRECHT A., DIETRICH W. and BERGER A.: Posthemorrhagic hydrocephalus in preterm infants: Long term follow-up and shunt related complications. Child's Nerv. Syst., 17: 663-9, 2001.

19- CIPRI S. and GAMBARDELLA G.: Neuroendoscopic approach to complex hydrocephalus. Personal experience and preliminary report. J. Neurosurg. Sci., 45: 92-6, 2001.

20- BERMAN P.H. and BAMKER B.Q.: Neonatal meningitis. A clinical and pathological study. Pediatrics, 38: 6-24, 1966.

21- BERMAN P.H. and BAMKER B.Q.: Neonatal meningitis. A clinical and pathological study. Pediatrics, 38: 6-24, 1966.

22- OI S. and ABBOTT R.: Loculated ventricles and isolated compartments in hydrocephalus: Their pathophysiology and the efficacy of neuroendoscopic surgery. Neurosurg. Clin. N. Am., Jan., 15 (1): 77-7. Review, 2004.

23- EL-GHANDOUR N.M.: Endoscopic cyst fenestration in the treatment of multiloculated hydrocephalus in children. J. Neurosurg. Pediatr., Mar., 1 (3): 217-22, 2008.

24- LEE Y.H., KWON Y.S. and YANG K.H.: Multiloculated Hydrocephalus: Open Craniotomy or Endoscopy? J. Korean Neurosurg. Soc., May, 60 (3): 301-5, 2017.

25- MATHIESEN T., GRANE P., LINDQUIST C. and VON HOLST H.: High recurrence rate following aspiration of colloid cysts in the third ventricle. J. Neurosurg., 78: 74852, 1993.

26- AKBARI S.H., HOLEKAMP T.F., MURPHY T.M., MERCER D., LEONARD J.R., SMYTH M.D., PARK T.S. and LIMBRICK D.D. Jr.: Surgical management of complex multiloculated hydrocephalus in infants and children. Childs. Nerv. Syst., Feb., 31 (2): 243-9, 2015.

27- VALENZUELA S. and TRELLEZ A.: Pediatric neuroendoscopy in Chile. Analysis of the first 100 cases. Child. Nerv. Syst., 15: 457-60, 1999.

28- OI S., HIDAKA M., HONDA Y., TOGO K., SHINODA M., SHIMODA M., TSUGANE R. and SATO O.: Neuroendoscopic surgery for specific forms of hydrocephalus. Child. Nerv. Syst., 15: 56-68, 1999.

29- SPENNATO P., CINALLI G., RUGGIERO C., ALIBERT F., TRISCHITTA V., CIANCIULLI E. and MAGGI G. Neuroendoscopic treatment of multiloculated hydrocephalus in children. J. Neurosurg., 106: 29-35, 2007.

30- KIM S.A., LETYAGIN G.V., DANILIN V.E., SYSOEVA A.A., RZAEV J.A. and MOISAK G.I.: The benefits of navigated neuroendoscopy in children with multiloculated hydrocephalus. Asian J. Neurosurg., 2017 Jul.-Sep., 12 (3): 483-8, 2017 


\section{فتح التكيسات بالمنظار لعلاج استسقاء الدماغ العاغ العاء متعدد التكيسات الناتج عن العدوى المئي}

خلفية: الاستسقاء الدماغى متعدد التكيسات هو مشكلة ناتجة عن تكن تكيسات اللسائل النخاعى داخل نسيج المخ والتى لا تكن متصلة

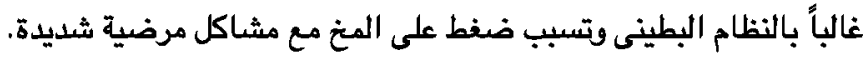

ويعتبر فتح التكيسات بالمنظار لعلاج استسقاء الد ماغ متعدد التكيسات هو تقنية جيدة مع نتائج أفضل بكثير من طرق آخرى. استسقاء

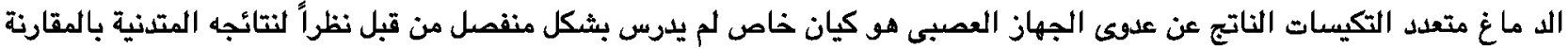
بالمسبيات الآخرى.

الآهداف: تهدف هذه الدراسة إلى تقييم النتائج الجراحية لفتح التكيسات بالمنظار لعلاج استسقاء الدماغ متعدد التكيسات الناتج عن

العنوى

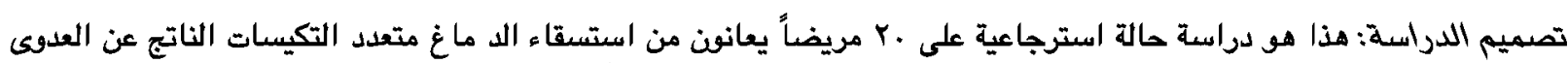

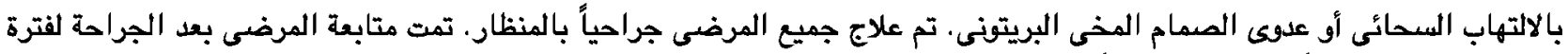

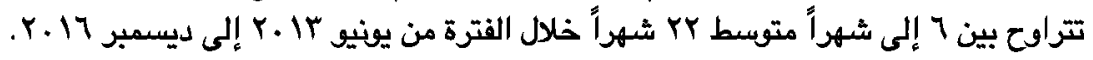

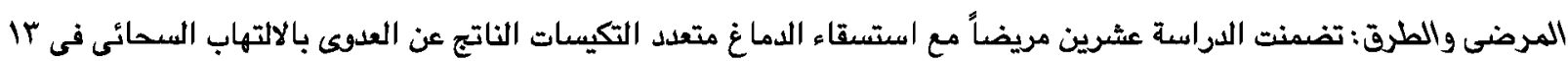

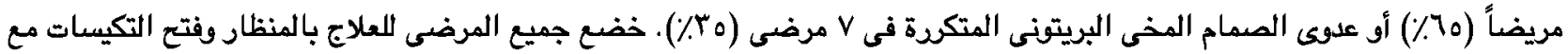

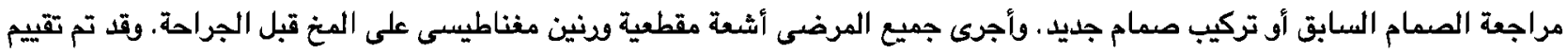

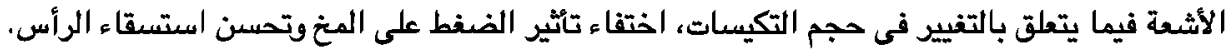

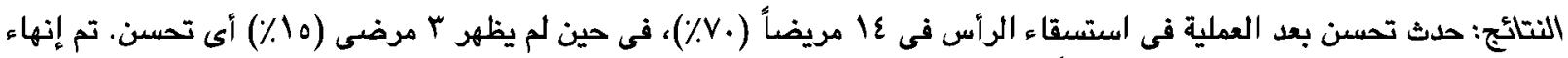

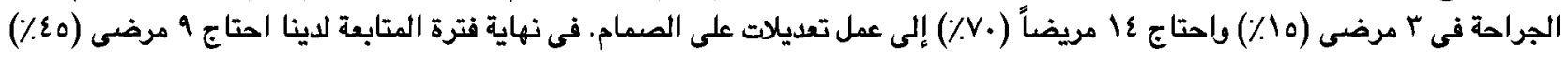

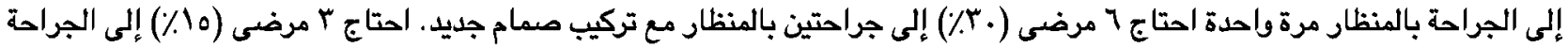

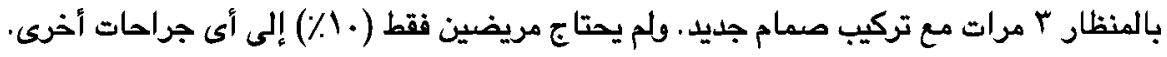

الاستتاج: استسقاء الد ماغ متعدد التكيسات هو مشكلة خطيرة ناجمة عن مسبيات مختلفة. ويستخدم المنظار الجراحى كخيار أول حيث

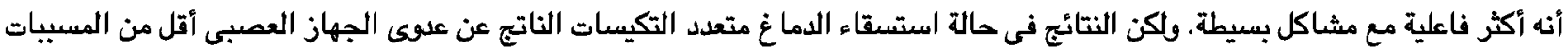

